\title{
Correlations of polyphenolic substances in Ribes aureum Pursh (Grossulariaceae) fruits
}

\author{
Vladimir Sorokopudov ${ }^{1 *}$, Alla Kuklina $^{2}$, Radmil Nigmatzyanov ${ }^{3-4}$, Olga Sorokopudova ${ }^{1}$, \\ and Nadezhda Nazaryuk ${ }^{5}$ \\ ${ }^{1}$ Russian State Agricultural University - K.A. Timiryazev Moscow Agricultural Academy, 127550, \\ Moscow, Russia \\ ${ }^{2}$ N.V. Tsitsin's Main Botanical Garden of the Russian Academy of Sciences, 127276, Moscow, \\ Russian Federation \\ ${ }^{3}$ Kushnarenkovsky Plant Breeding Center for Fruit-Berry Crops and Grapes of the Bashkir Research \\ Agricultural Institute, 420076, Ufa, Bashkortostan republic, Russia \\ ${ }^{4}$ Institute of Strategic Research of Bashkortostan Republic, 450008, Ufa, Russia \\ ${ }^{5}$ Federal State Budgetary Scientific Institution of the Federal Altai Scientific Center for Agricultural \\ Biotechnologies, 656910, Barnaul, Russia
}

\begin{abstract}
The morphometric parameters of fruits (yield, weight) were revealed and the quantitative determination of anthocyanins and carotenoids in the fruits of golden currant (Ribes aureum Pursh) was carried out using the methods of spectrophotometry and reverse-phase high-performance liquid chromatography. The cultivar specificity in the content of anthocyanins and carotene in $R$. aureum fruits was established. There is a direct correlation between the anthocyanin and carotene content, which allows assessing the biological activity more accurately. No correlation was found between the morphometric and biochemical characteristics of $R$. aureum fruits.
\end{abstract}

Keywords: polyphenolic substances, Ribes aureum Pursh, anthocyanins, carotenoids.

\section{Introduction}

Oxidative damages occur when plants are exposed to various external factors or when a sudden change in the plant physiological state occurs. A sufficient resistance to them is due to the existence of effective plant cell protective systems, which are based on antioxidants. The antioxidant activity, which reflects the effect of all organic reducing agents present in an object, is associated with the stress effect on an organism. The ecological aspect of antioxidant accumulation in plants attracts the attention of researchers and needs a further study. The practical use of plants and the products obtained from them with the antioxidant activity in modern conditions become increasingly important [1-6].

The content of the substances of phenolic origin was observed in the species of genus Ribes L. (Grossulariaceae DC.). R. aureum Pursh berries contain significant amounts of biologically active substances with antioxidant activity: ascorbic acid and anthocyanins, as

\footnotetext{
* Corresponding author: sorokopud2301@mail.ru
} 
well as carotenoids [7-8]. Species of genus Ribes are characterized by a high content of secondary metabolites. The synthesis of anthocyanins in the fruits of $R$. aureum begins in mid-late June, visually accompanied by the fruits color transition from green to brown and then to black. The content of anthocyanins steadily increases until mid-late July, and then decreases with a continued weight gain; this indicates that the process of anthocyanin synthesis in fruits stops at a certain stage [9-10].

The chromatographic profile of the anthocyanin complex in the studied fruits of $R$. nigrum L. and $R$. aureum is qualitatively almost unchanged. It contains delphinidin-3glucoside (D3G)-delphinidin-3- utinoside (D3R)-cyanidin-3-glucoside (C3G)-cyanidin-3rutinoside (C3R) [9-10]. However, correlations between biologically active substances and pigments, for example, carotenoids in $R$. aureum, as well as morphometric parameters, have not been studied. $R$. aureum anthocyanins are represented almost exclusively by cyanidin (glucoside and rutinoside), and the proportion of delphinidin glycosides in a number of samples is reduced to minor components [11-14].

The aim of the present work was to determine the relationship between antioxidants and the morphometric characteristics of $R$. aureum, as well as to clarify their cultivar specificity.

\section{Materials and methods}

The object of the study was $R$. aureum, introduced in the Botanical Garden of the Belgorod State National Research University, Main Botanical Garden of the Russian Academy of Sciences and the Bashkir Research Institute of Agricultural Sciences (2010-2018)/

The yield of $R$. aureum and other economic and biological indicators were determined according to the "Program and methods of fruit, berry and nut crops selection" [15].

The quantitative determination of biologically active substances was carried out in liquid $R$. aureum fruit extracts using the methods of spectrophotometry and reverse-phase high-performance liquid chromatography (HPLC). Purification of biologically active substances was carried out by flash chromatography in normal-phase and reverse-phase versions on concentrating DIAPAC cartridges according to the previously described method [16]. The spectra in the UV and visible regions of the electromagnetic spectrum were recorded on the KFK-3-01device. Anthocyanin extracts were obtained by several times infusing freshly picked fruits in the $0.1 \mathrm{M}$ aqueous hydrochloric acid solution until the initial material was discolored [16-17]. We performed computer statistical data processing using the "Stadia" 7.0 software package.

\section{Experimental}

The $R$. aureum fruits are distinguished by the absence of delphinidin bases as in gooseberries (Grossularia). Such a composition of anthocyanin components can characterize the enzymatic system of $R$. aureum by the absence of flavonol 3'- and 5'hydroxylases. The proportions of glucoside and rutinoside components in different years of observation are approximately equal, with a possible slight predominance of 3-rutinosides. The content of anthocyanins and carotenoids in the $R$. aureum fruits is shown in Table 1.

We found positive correlations between the content of anthocyanins and carotene in the fruits of $R$. aureum ( $\mathrm{rs}=0.9(\mathrm{P}<0.05)$ ), and this fact allows us to predict the changes in these substances. No correlation was found between the content of ascorbic acid and anthocyanin, as well as between the morphometric and biochemical characteristics of the $R$. aureum fruits. 
Table 1. Content of anthocyanins and carotenoids in Ribes aureum fruits cultivated in the Bashkir Research Institute of Agriculture (2010-2018)

\begin{tabular}{|c|c|c|}
\hline Genetic forms & Content of anthocyanins, $\mathbf{~ m g} \mathbf{1 0 0 g}$ & Content of carotenoids, $\mathbf{~ g / 1 0 0 g}$ \\
\hline $1-6$ & $316.7 \pm 32.5$ & $19.4 \pm 2.1$ \\
\hline $3-3$ & $134.7 \pm 14.1$ & $11.8 \pm 1.1$ \\
\hline $5-3$ & $456.0 \pm 35.0$ & $22.8 \pm 2.2$ \\
\hline $6-7$ & $26.5 \pm 2.5$ & $6.3 \pm 0.6$ \\
\hline $7-3$ & $332.8 \pm 31.0$ & $19.7 \pm 1.9$ \\
\hline $7-8$ & $11.4 \pm 1.1$ & $4.8 \pm 0.4$ \\
\hline $1-15$ & $1240 \pm 127.0$ & $25.4 \pm 2.5$ \\
\hline $1-18$ & $565.1 \pm 45,6$ & $23.7 \pm 2.3$ \\
\hline $1-19$ & $134.8 \pm 12.8$ & $11.8 \pm 1.2$ \\
\hline $1-24$ & $428.2 \pm 41.2$ & $22.0 \pm 2.2$ \\
\hline $2-48$ & $106.2 \pm 10.4$ & $9.3 \pm 1.1$ \\
\hline $2-49$ & $447.6 \pm 43.8$ & $22.4 \pm 2.1$ \\
\hline $2-52$ & $342.2 \pm 31.5$ & $21.0 \pm 1.8$ \\
\hline $2-53$ & $194.2 \pm 18.9$ & $13.6 \pm 1.4$ \\
\hline $3-05$ & $18.7 \pm 9.2$ & $7.7 \pm 0.9$ \\
\hline $3-07$ & $274.9 \pm 26.7$ & $19.7 \pm 1.9$ \\
\hline $3-08$ & $252.4 \pm 23.4$ & $15.7 \pm 1.5$ \\
\hline $3-10$ & $371.0 \pm 30.9$ & $20.8 \pm 2.0$ \\
\hline $3-18$ & $423.5 \pm 41.0$ & $21.3 \pm 2.1$ \\
\hline $3-20$ & $71.1 \pm 6.7$ & $8.4 \pm 0.8$ \\
\hline $3-21$ & $103.0 \pm 9.8$ & $8.9 \pm 0.9$ \\
\hline $3-25$ & $394.0 \pm 38.8$ & $21.8 \pm 1.9$ \\
\hline $3-40$ & $78.7 \pm 7.9$ & $8.7 \pm 0.7$ \\
\hline $6-10$ & $386.0 \pm 36.8$ & $21.0 \pm 2.1$ \\
\hline Venera 0 & $247.8 \pm 21.7$ & $15.2 \pm 1.6$ \\
\hline & & \\
\hline & & \\
\hline
\end{tabular}

The morphometric and biochemical characteristics of Ribes aureum fruits are presented in Table 2.

Table 2. Morphometric and biochemical characteristics of $R$. aureum cultivars in the Botanical Garden of the Belgorod State National Research University (2015-2018)

\begin{tabular}{|c|c|c|c|c|c|c|c|}
\hline \multirow{2}{*}{ Cultivar } & \multicolumn{2}{|c|}{$\begin{array}{l}\text { Yield, } \\
\text { kg/bush }\end{array}$} & \multicolumn{2}{|c|}{$\begin{array}{c}\text { Fruit weight, } \\
\mathrm{g}\end{array}$} & \multirow{2}{*}{$\begin{array}{c}\text { Content of } \\
\text { ascorbic acid in } \\
\text { berries, mg \% }\end{array}$} & \multirow{2}{*}{$\begin{array}{c}\text { Content of } \\
\text { anthocyanins, } \\
\text { mg \% }\end{array}$} & \multirow{2}{*}{$\begin{array}{c}\text { Content of } \\
\text { carotene, } \mathrm{mg} \\
\%\end{array}$} \\
\hline & $\overline{\mathbf{X}}$ & $\max$ & $\overline{\mathbf{X}}$ & $\max$ & & & \\
\hline Businka & $4.8 \pm 0.3$ & 5.0 & $0.9 \pm 0.1$ & 3.3 & $102.8 \pm 4.5 * *$ & $143.9 \pm 3,4 * *$ & $11.5 \pm 0.8 * *$ \\
\hline Dragunskaya & $4.2 \pm 0.4$ & 5.0 & $1.5 \pm 0.2$ & 2.3 & $78.5 \pm 3.5 * *$ & $115.4 \pm 2,5 *$ & $7.9 \pm 0.5 *$ \\
\hline $\begin{array}{c}\text { Medovy } \\
\text { Spas }\end{array}$ & $3.6 \pm 0.2$ & 5.0 & $1.9 \pm 0.3$ & 3.5 & $44.3 \pm 2.5$ & $184.8 \pm 4,7 * *$ & $12.3 \pm 1.1 * *$ \\
\hline Sensans & $4.2 \pm 0.3$ & 5.0 & $0.9 \pm 0.1$ & 3.3 & $22.9 \pm 0.8 *$ & $264.5 \pm 5,9 * *$ & $16.7 \pm 1.2 * *$ \\
\hline $\begin{array}{c}\text { Venera } \\
\text { (control) }\end{array}$ & $4.5 \pm 0.5$ & 5.0 & $0.8 \pm 0.1$ & 1.4 & $45.1 \pm 2.7$ & $103.1 \pm 2,4$ & $6.4 \pm 0.4$ \\
\hline
\end{tabular}


Note: *differences from the control are significant $(\mathrm{P}<0.05)$; **differences from the control are significant $(\mathrm{P}<0.01)$.

\section{Results and discussion}

In the $R$. aureum fruit extract, the main maximum is at $442.5 \mathrm{~nm}$. The nature of the spectrum suggests the presence of $\beta$-carotene in the extract (or its derivatives, $\beta-$ cryptoxanthin or zeaxanthin, which are similar in the structure and arrangement of conjugated double bonds). At the same time, the total content of carotenoids (in terms of $\beta$ carotene) in different forms was from 8 to $19 \mathrm{mg} \%$, and the maximum content of these biologically active substances is typical of the most dark-colored forms $[9,15]$. The results of the conducted studies coincide with those obtained by other authors, where golden currant in the Altai conditions contains from 5 to $12 \mathrm{mg} \%$ of carotenoids. It should be noted that the extraction of pigments separately from the skin and separately from the pulp allowed us to establish that the concentration of carotenoids occurs in the skin, where their content exceeds the total more than 4 times.

\section{Conclusions}

1. The cultivar specificity in the content of anthocyanins and carotene in the R. aureum fruits was established.

2. The existence of direct correlations between the content of anthocyanins and carotene makes it possible to produce the interchangeability of parameters when used in the assessment of biological activity.

3. R. aureum is characterized by the presence in the fruit of a significant amount of carotenoids represented mainly by $\beta$-carotene.

\section{References}

1. G.I. Vysochina, Phenolic compounds in the systematics and phylogeny of the buckwheat (Polygonaceae) family (RAS publ., Novosibirsk, 2004).

2. M.E. Zhavaronkova, N.S. Fursa, M.V. Belousov, Pharmatsia publ., 2, 12-14 (2007)

3. M.E. Zhavoronkova, N.S. Fursa, M.V. Belousov, Acad. of Sci., 3/1 (37), 58 (2011).

4. N.M. Kaznina, A.F. Titov, L.V. Topchieva, G.F. Laidineng, Yu.V. Batova, Plant Phys. j., 59, 1 (2012).

5. I.L. Fuksman, Plant Research j., 39, 2 (2003).

6. I.A. Prokopyev, G.V. Filipova, A.A. Shein, Plant phys., 59, 2 (2012).

7. A.V. Karakulov, E.A. Karpova, V.G. Vasilyev, Ecological-geographical variability of morphometric parameters and flavonoid composition of Rhododendron parvifolium, Turczaninowia, 21 (2) (2018).

8. Yu.D. Goryunova, Effect of ecological factors on the content of some antioxidants in plants, author's abstract of PhD thes. in biol. sci., Kaliningrad, 22 (2009).

9. E.I. Shaposhnik, L.A. Deineka, V.N. Sorokopudov, V.I. Deineka, Yu.V. Burmenko, V.V. Kartushinsky, A.V. Tregubov, Sci. rep. of Belgorod State University, Nat. sci. series, 9 (104), 15/2 (2011).

10. V.I. Deineka, V.N.Sorokopudov, L.A.Deineka, E.I.Shapashnik, J.V. Burmenko, Sci. rep. of Belgorod State University, Medicine series, Pharmatsia, 18 (161), 23 (2013). 
11. R.A. Nigmatzyanov, V.N. Sorokopudov, A.G.Kuklina, Krasnoyarsk State Agricultural University News Bullet., 3 (2020), DOI:10.36718/1819-4036-2020-3-29-34.

12. E.A Solomatina, N.M. Solomatin, V.N. Sorokopudov, O.A. Sorokopudova, N.I. Myachikova, Frum Adina, Georgescu Cecilia, Development and analysis of fruit beverages with antioxidant properties, Scientific Study and Research : Chemistry and Chemical Engineering, Biotechnology, Food Industry j., 21, 4 (2020).

13. F.F. Sazonov, S.N. Evdokimenko, V.N. Sorokopudov, N.V. Andronova, D.N. Skovorodnikov, Acta Horticulturae j., 1277 (2020).

14. R.A. Nigmatzyanov, V.N. Sorokopudov, Krasnoyarsk State Agricultural University News Bullet., 1 (2020), DOI:10.36718/1819-4036-2020-1-34-39.

15. E.N. Sedov, T.P. Ogoltsova Program and methods of fruit, berry and nut crops breeding (All-Russ. Research Inst. of Fruit Crops Breeding publ., Orel, 1999)

16. V.I. Deineka, A.M. Grigoryev, L.A. Deineka, E.I. Shaposhnik, V.M. Staroverov, Plant Laboratory j. Material Diagnostics, 72, 3 (2006).

17. J.M. Cheeseman, Hydrogen Peroxide and Plant Stress: A Challenging Relationship. Plant Stress (Global Sci. Books, 2007). 